\title{
Significance of intratissue estrogen concentration coupled with estrogen receptors levels in colorectal cancer prognosis
}

\author{
Agnieszka Anna Rawłuszko-Wieczorek¹, Łukasz Marczak², Nikodem Horst ${ }^{3, *}$, \\ Karolina Horbacka ${ }^{3, *}$, Piotr Krokowicz ${ }^{3}$ and Paweł Piotr Jagodziński ${ }^{1}$ \\ ${ }^{1}$ Department of Biochemistry and Molecular Biology, Poznań University of Medical Sciences, Poznan, Poland \\ ${ }^{2}$ European Centre for Bioinformatics and Genomics, Institute of Bioorganic Chemistry, Polish Academy of Sciences, \\ Poznan, Poland \\ ${ }^{3}$ Department of General and Colorectal Surgery, Poznań University of Medical Sciences, Poznan, Poland \\ *These authors have contributed equally to this work
}

Correspondence to: Agnieszka Anna Rawłuszko-Wieczorek, email: arawluszko@ump.edu.pl

Keywords: estrogen; estrogen receptors; colorectal cancer

Received: April 28, $2017 \quad$ Accepted: December 05, 2017 Published: December 14, 2017

Copyright: Rawłuszko-Wieczorek et al. This is an open-access article distributed under the terms of the Creative Commons Attribution License 3.0 (CC BY 3.0), which permits unrestricted use, distribution, and reproduction in any medium, provided the original author and source are credited.

\section{ABSTRACT}

Dysregulation of estrogen related pathways is implicated colorectal cancer (CRC) development. However, significance of intratissue concentration of estrone (E1) and $17 \beta$-estradiol (E2) in relation to estrogen receptor (ESR) expression level was not addressed so far. Herein, we measured E1 and E2 intratissue concentration using liquid chromatography electrospray ionization tandem mass spectrometry (ESI LC/MS) and mRNA levels of ESR1 and ESR2 using RT-qPCR in cancerous and histopathologically unchanged tissue from 75 and 110 CRC patients, respectively. The obtained results were associated with clinicopathological factors, expression of estrogen dependent genes (CTNNB1, CCND1) and prognostic significance. We found no statistically significant differences in E1 or E2 concentration between cancerous tissue and histopathologically unchanged counterparts. Moreover, mRNA levels of ESR1 and ESR2 were significantly decreased in cancerous tissue compared with histopathologically unchanged $(p=0.00001)$. Log rank analysis revealed no benefit of low E1 to E2 ratio, high E1, E2 concentration or ESR1, ESR2 mRNA level for patients' overall (OS) and disease free survival (DFS). Interestingly, we have observed that patients with low ESR1 mRNA level coupled with low E1 intratissue concentration had a significant decrease in DFS compared with group of patients with high ESR1 mRNA level and high E1 concentration ( $H R=0.16,95 \% \mathrm{CI} 0.02-1.05 ; p=0.06)$. Furthermore, patients with low E1 concentration and low ESR1 transcript had significantly higher CTNNB1 and CCND1 mRNA level compare with subgroup with high level of both grouping factors. Our study indicates a potential value of estrogen intratissue concentration and its receptor expression level for CRC patients' prognosis.

\section{INTRODUCTION}

Even though multiple factors are involved in colorectal cancer (CRC) development the CRC occurs less frequently among women in all susceptibility groups [1]. Gender differences suggest potent role of steroid hormones. Premenopausal women have lower CRC incidence than age-matched men [2, 3]. Additionally, most of the prospective and retrospective studies showed an inverse relationship between the risk of CRC incidence and the use of hormone replacement therapy (HRT) by postmenopausal women [4-6]. Moreover, in animal studies, ovariectomized rats exposed to estrone had significantly reduced tumor growth [7] whereas 
ovariectomized $\mathrm{Apc}^{\mathrm{Min} /+}$ mice had increased number of polyp formation [8].

Interestingly, metabolism of estrogen, including the synthesis of most biologically active form, 17 $\beta$-estradiol (E2), may take place in peripheral tissues, including the large bowel. Estrone (E1) can be produced in extragonadal tissues from C19 precursors via the sulfatase or aromatase pathway [9]. Subsequently, E1 may be converted into E2 by $17 \beta$-hydroxysteroid dehydrogenases (HSD17 $\beta$ s) [9].

Further, estrogen manifest its cellular effect primarily by estrogen receptors ER- $\alpha$ and $-\beta$, encoded by ESR 1 and ESR2 respectively [9]. Importantly, ESR2 expression was inversely correlated with CRC progression and $\mathrm{dKO}$ of Esr1 or Esr2 in ovariectomized $\mathrm{Apc}^{\mathrm{Min} /+}$ resulted in increased rate of tumor formation [10-13].

Despite of potential significance of estrogen metabolism within peripheral tissues, the concentrations of intratissue estrogens were only once investigated in CRC clinical samples. Moreover, CRC risk may differ depending on the expression level of ERs. Therefore, we measured E1 and E2 levels in cancerous and histopathologically unchanged tissue from 75 CRC patients' samples as well ESR1 and ESR2 mRNA levels from 110 patients. Next we addressed the question if expression level of ER in relation to matched intratissue estrogen concentration affects patients' clinical outcome.

\section{RESULTS}

\section{Intratumoral concentrations of $\mathrm{E} 1$ and $\mathrm{E} 2$ in cancerous and adjacent histopathologically unchanged colorectal tissue}

The levels of intratissue estrogens were measured in 75 patients in cancerous and adjacent histopathologically unchaged tissue using ESI LC/MS. The median values for E1 were 1.5- fold higher in cancerous tissue compared with histopathologically unchanged (Figure 1A). However, observed trend have not reach statistically significant threshold probably due to high divergence of samples (range: $1.22-304.98 \mathrm{pmol} / \mathrm{g}$ for cancerous tissue; $0.59-250.18 \mathrm{pmol} / \mathrm{g}$ for histopathologcally unchanged; $\mathrm{p}=0.30$ ). In the same sample set E2 concentration was only 1.15 higher in histopathologically unchanged tissue without statistical significance $(\mathrm{p}=0.36)$ with sample range $0.13-72.98 \mathrm{pmol} / \mathrm{g}$ for histopathologically unchanged and 0.0025-34.61 pmol/g for cancerous tissue. No statistical change was also identified in different age groups, genders, CRC localizations and histologic grades for E1 and E2 (Supplementary Table 1). TNM stratification revealed statistically significant higher E2 concentration in histopathologically unchanged tissue than cancerous in IIIB group (Supplementary Table 1). However, the detected outcome is an effect of other observation. Categorical clustering for histopathologically unchanged tissue indicated significant differences $(p=0.031)$ with bias toward higher E2 concentration in IIIB and IIIC group compared with I and IIA (not significant in post-hoc analysis, Figure 1B; Supplementary Table 2). Moreover, the E1 concentration was significantly higher in patients above 60 yrs within cancerous tissue (post-hoc $=0.01$; Figure 1C, Supplementary Table 2).

Importantly, E1 and E2 intratumoral levels were significantly correlated in histopathologically unchanged and cancerous tissue (Figure 1D). Subsequently, we analyzed E1 to E2 ratio from the same samples. We have observed that E1 to E2 ratio increased markedly in cancerous tissue compared with histopathologically unchanged $(p=0.0063$; Figure 2). Furthermore, we observed statistically higher E1 to E2 ratio in: patients above 60 years; men; tumor localized in proximal colon and rectum; histological grade G2 and G3 as well patients with TNM grade IIIB (Supplementary Table 3). At the same time, categorical analysis did not show statistically significant bias toward any group (Supplementary Table 2).

\section{ESR1 and ESR2 mRNA level is decreased in primary cancerous tissue compared with histopathologically unchanged from 110 patients with CRC}

To evaluate the ESR1 and ESR2 transcript level in cancerous and histopathologically unchanged tissues from one hundred ten patients with CRC we used RT-qPCR. We found significantly lower level of ESR1 and ESR2 transcript $(p<0.0001)$ in primary cancerous than in the histopathologically unchanged tissues in patients with CRC (Figure 3A). Moreover, we observed significantly lower level of analyzed mRNAs in cancerous tissues in different age groups, genders, CRC localizations, histologic grades and TNM stages (Supplementary Table 4). We also detected statistically significant correlation of ESR1 and ESR2 mRNA levels in histopathologically unchanged and cancerous tissue (Figure 3B).

\section{Correlation between intratumoral estrogens concentrations and estrogens receptors mRNA levels with clinical outcome of CRC patients}

To investigate the effect of ESR1 and ESR2 transcript levels and E1 and E2 concentrations on patients' survival we carried out retrospective clinical analysis. The median overall survival (OS) was 49 months (range: 4-80 months) and DFS 40 (range: 5-80). Based on RTqPCR for ESR1 and ESR2 mRNA levels and on ESI LC/MS results for E1 and E2 concentration, cancerous tissue measurements were subdivided into three groups of similar size: low, intermediate and high transcript levels or estrogen concentration. Univariate analysis revealed no benefits of high ESR1 or ESR2 mRNA levels for patients' OS and DFS survival (Supplementary Figure 1). 

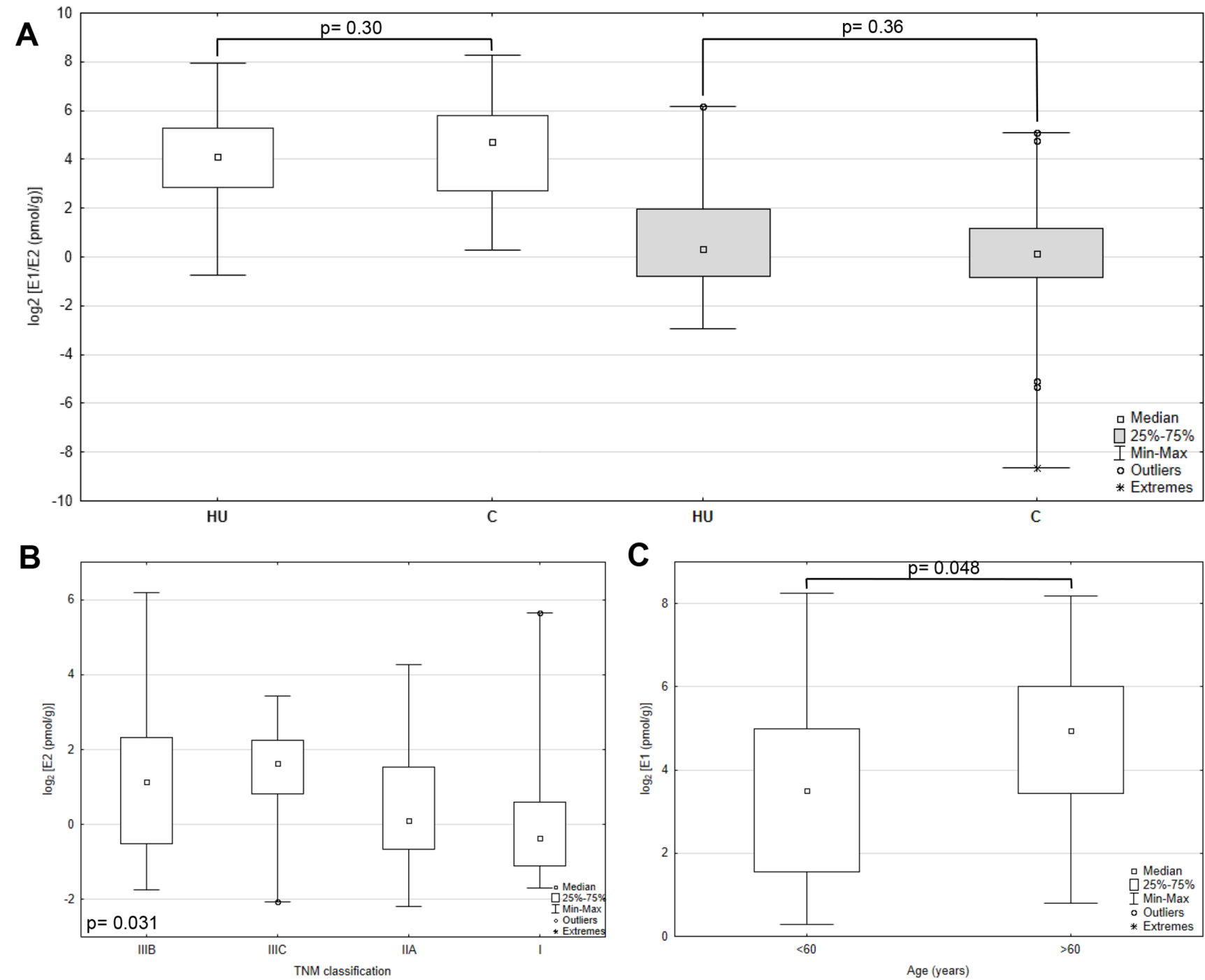

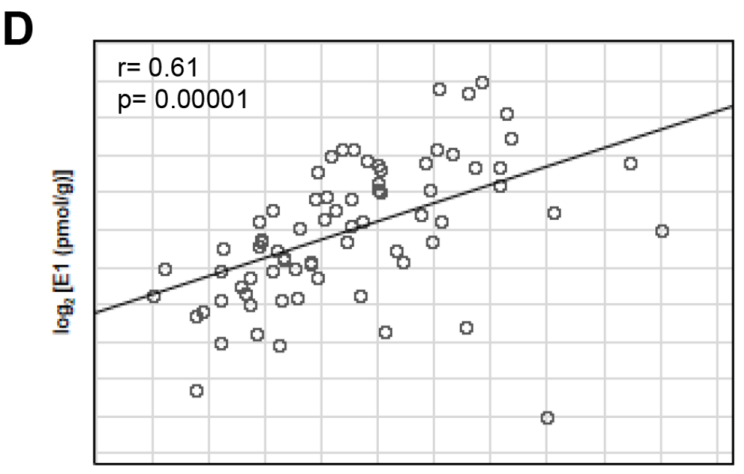

$\log _{2}[E 2(\mathrm{pmol} / \mathrm{g})]$

HU

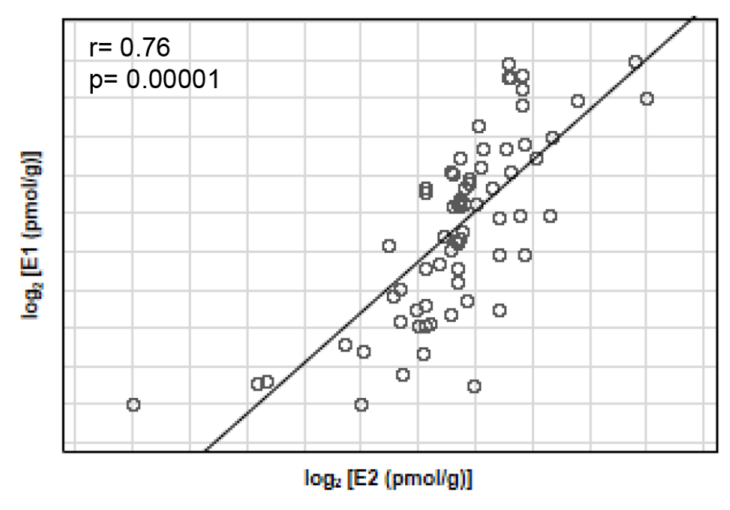

C

Figure 1: Intratissue estrone (E1) and estradiol (E2) concentrations in primary cancerous and histopathologically unchanged tissues from patients with CRC. (A) The cancerous (C) and histopathologically unchanged tissues (HU) from 75 patients with CRC were used for steroid fraction isolation, derivatization and measurement using ESI LC/MS. E1- white boxes; E2- grey boxes. (B) E2 concentrations isolated from cancerous tissue classified according to TNM: group IIIB, IIIC, IIA and I. (C) E1 concentrations isolated from cancerous tissue classified according to patients age at the time of tumor resection. (D) Correlation of intratissue E1 and E2 concentrations isolated from cancerous (C) and histopathologically unchanged tissues (HU) from 75 patients with CRC. The amounts of E1 and $\mathrm{E} 2$ are presented as $\log _{2}$ - transformed data. 


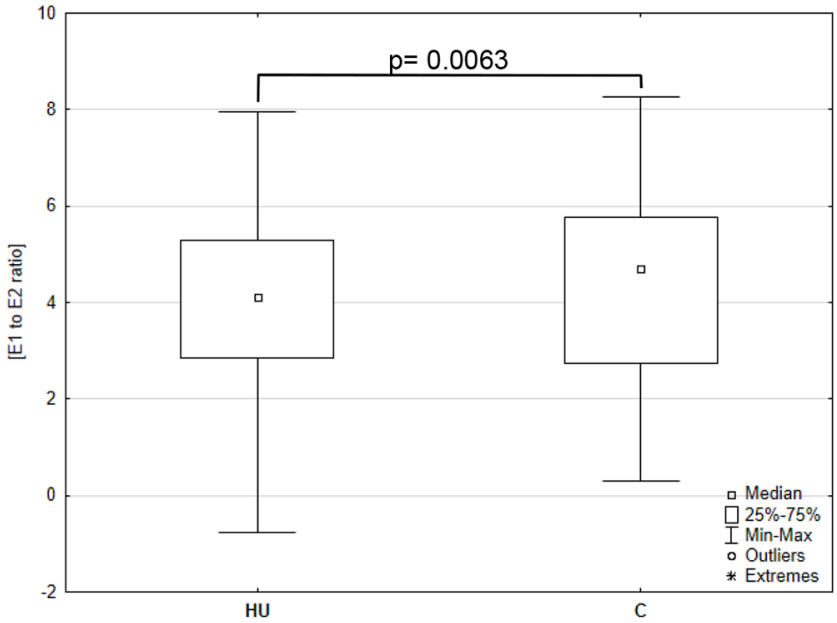

Figure 2: Intratissue estrone (E1) to estradiol (E2) ratio in primary cancerous and histopathologically unchanged tissues from patients with CRC. The cancerous (C) and histopathologically unchanged tissues (HU) from patients with CRC were used for steroid fraction isolation, derivatization and measurement using ESI LC/MS. E1 to E2 ratio was given for the 67 samples in cancerous and 73 in histopathologically unchanged CRC tissue.

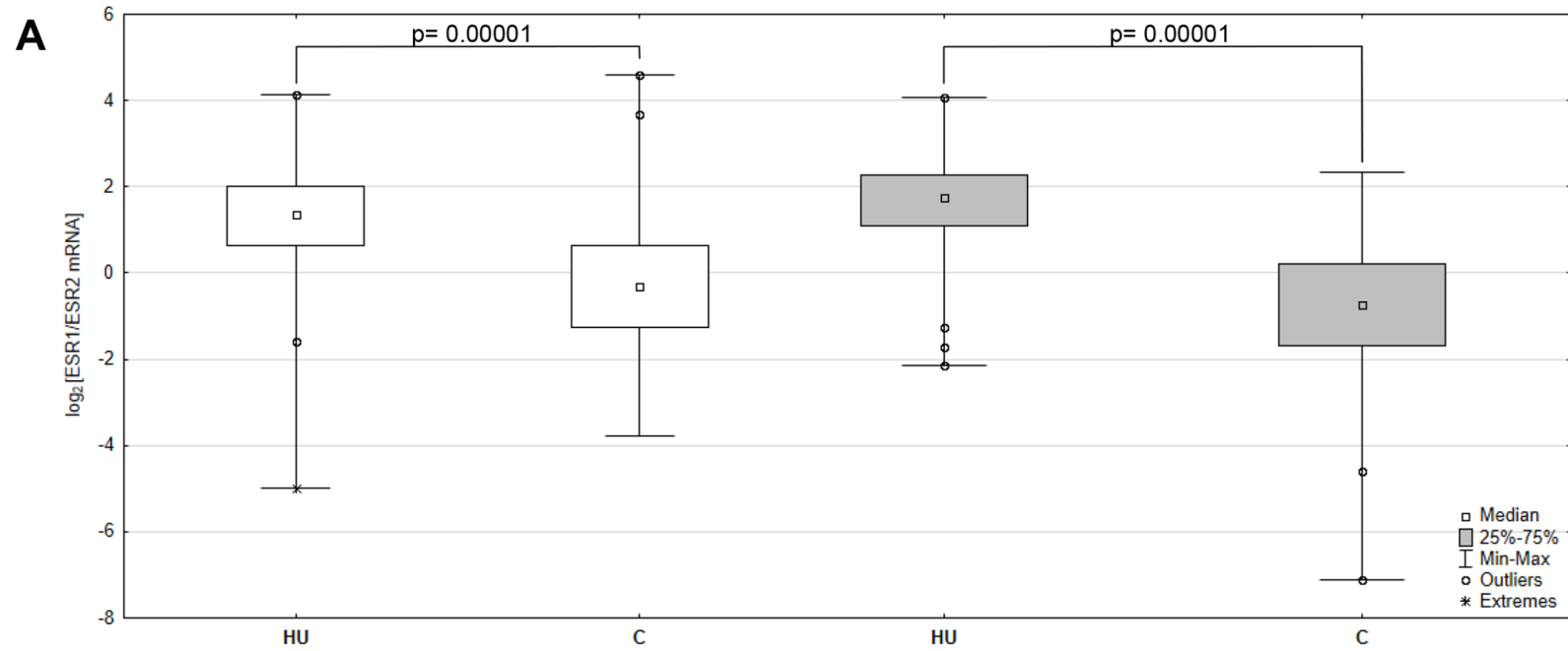

B

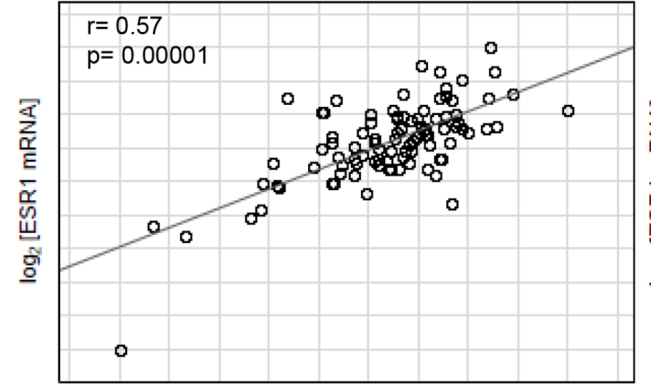

$\log _{2}[\mathrm{ESR} 2 \mathrm{mRNA}]$

HU

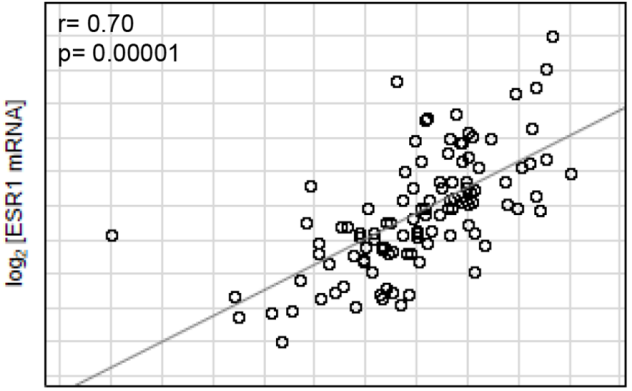

$\log _{2}[E S R 2$ mRNA]

C

Figure 3: ESR1 and ESR2 transcript levels in primary cancerous and histopathologically unchanged tissue from patient with CRC. (A) The primary cancerous tissues from 110 patients with CRC were used for RNA isolation. Total RNA was reversetranscribed, and cDNAs were investigated by RQ-PCR relative quantification analysis. The ESR1 and ESR2mRNA levels were corrected by the geometric mean of PBGD and hMRPL19 cDNA levels. ESR1- white boxes; ESR2- grey boxes. (B) Correlation of ESR1 and ESR2 transcript levels from cancerous (C) and histopathologically unchanged tissues (HU) from 110 patients with CRC. The amount of ESR1 and ESR2 mRNA was expressed as the $\log _{2}$ of multiples of cDNA copies in the calibrator. 
Moreover, even though median survival age was longer for group of patients with higher E1 and E2 concentration, the results were not statistically significant considering completed and censored patients' cases (Supplementary Figure 1). Similarly, there was no evidence of impact of E1 to E2 ratio on OS and DFS in cancerous tissue (Supplementary Figure 1).

To better explore prognostic potential of intratissue estrogen in CRC we associated this etiological factor with molecular subgroups (expression levels of ESRs). Samples were subdivided into four categorical groups: low E1(E2) and low ESR1(ESR2); low E1(E2) and high ESR1(ESR2); high E1(E2) and high ESR1(ESR2); high E1(E2) and low ESR1(ESR2). Interestingly using log rank test, we observed that patients with coupled low E1 concentration and low ESR1 mRNA level had a significant increase in disease recurrence compared with patients with high E1 concentration and high ESR1 mRNA level ( $p=0.02$; Figure 4A). This related to survival: 24 months in first subgroup versus 59.5 in second one (Figure 4A). Additionally, we observed benefit of high E1 concentration combined with high ESR2 transcript level for patients' OS. There was a 20 months' increase in OS survival compared with subgroup with low in both E1 concentration and ESR2 transcript level (Figure 4B). Although, result for E1 combined with ESR1 for OS was statistically insignificant, it suggests that there may have been a reduction in the risk of death for patients with high E1 concentration and ESR1 transcript level (Figure 4A). Combination of E1 with ESR2 for DFS and all E2 related groups disclosed lack of impact on OS and DFS survival (Figure 4C, 4D). Following, multivariate Cox regression analysis with respect to age, gender and post-operative chemotherapy status revealed that ESR 1 mRNA level and E1 concentration can be together prognostic factors for patient's survival (Table 1). We observed moderate effect of high E1 coupled with high ESR1 transcript level on patients' OS with HR equal 0.15 (95\% CI: 0.02-1.25; $\mathrm{p}=0.08$ ) (Table 1). The effect was also significantly beneficial for any combination of high ESR1 transcript or E1 concentration for patients' DFS (Table 1). The effect of E1 coupled with ESR2 on patients' OS was not preserved in multivariate analysis (Table 1).

\section{ESR1 low mRNA level together with low E1 concentration is associated with higher transcript levels of $\beta$-catenin and cyclin D1 in cancerous tissue of CRC patients}

Previous studies suggest influence of estrogenic signaling on Wnt pathway. In $\mathrm{Apc}^{\mathrm{Min} /+}$ mice $\beta$-catenin expression, encoded by $C T N N B 1$, was higher in ER- $\alpha$ deficient mice, that followed overexpression of Wnt activated genes including cyclin D1, encoded by CCND1 [11]. Hence we have evaluated effect of intratissue estrogen concentration and ESR 1 and ESR2 expression on CTNNB1 and CCND1 mRNA level. As expected, expression of both CCND1 $(\mathrm{p}=0.000016)$ and $C T N N B 1$ $(\mathrm{p}<0.000001)$ was strongly upregulated in CRC patients compared with histopathologically unchanged tissue (Supplementary Figure 2). Following, estrogen receptors mRNA level and estrogen concentration was inversely correlated with $C T N N B 1$ transcript levels whereas only estrogen receptors were negatively correlated with CCND1 transcript (Figure 5). Moreover, CTNNB1 mRNA level was significantly reduced in cancerous tissue with simultaneously high ESR1 transcript and E1 concentration as compared with expression level in group with low E1 level and low or intermediate ESR1 mRNA level (Figure 6). For group intermediately expressing ESR1 we observed significant decrease of CTNNB1 transcript as E1 level was higher. Same inverse correlation we observed for CCND1 mRNA level (Figure 6). CCND1 transcript was significantly lower in samples expressing high ESR1 level regardless of E1 level as compared with samples with low ESR1 level and high E1 concertation (Figure 6). Significant differences were also seen for CTNNB1 transcript when we analyzed E1 together with ESR2 status (Supplementary Figure 3). We have also detected moderate inverse relation of CTNNB1 and CCND1 mRNA level with ESR1 and E2 level (Supplementary Figure 3). Surprisingly we have not observed clear influence of ESR2-E2 on CTNNB1 nor CCND1 (Supplementary Figure 3). Only subgroup intermediately expressing E2 and ESR2 presented significantly lower mRNA level of both transcripts (Supplementary Figure 3).

\section{DISCUSSION}

Estrogen related pathways are implicated in gene expression regulation and homeostasis of many tissues and consequently are often altered in numerous pathophysiological conditions including cancer. Numerous evidences associate estrogen with CRC occurrence. Recent metaanalysis summarizes observational studies and confirm link of HRT usage with decrease in CRC incidence [14]. Even though results seems to be reproducible some reports present contrary data, which may be consequence of various observational studies aspects: usage of different hormones formulations or variation in HRT-start point in relation to menopause [15]. At the same time, studies related to blood circulating estrogens rather relate high estrogens concentrations with the CRC risk or report no relevant connection [16-19]. Only recent publication inversely associates endogenous E1 and E2 with CRC risk [20]. Estrogens are also thought to lower severity of the inflammatory bowel disease (IBD) $[21,22]$. Importantly, extragonadal tissues, including colon, may produce E1 and E2 from circulating precursors by aromatase or sulfatase pathway [9]. Our and other groups' data prove alterations of enzymes activity involved in estrogen metabolism in CRC [23-26]. Active intratissue estrogen metabolism raises the question about significance 

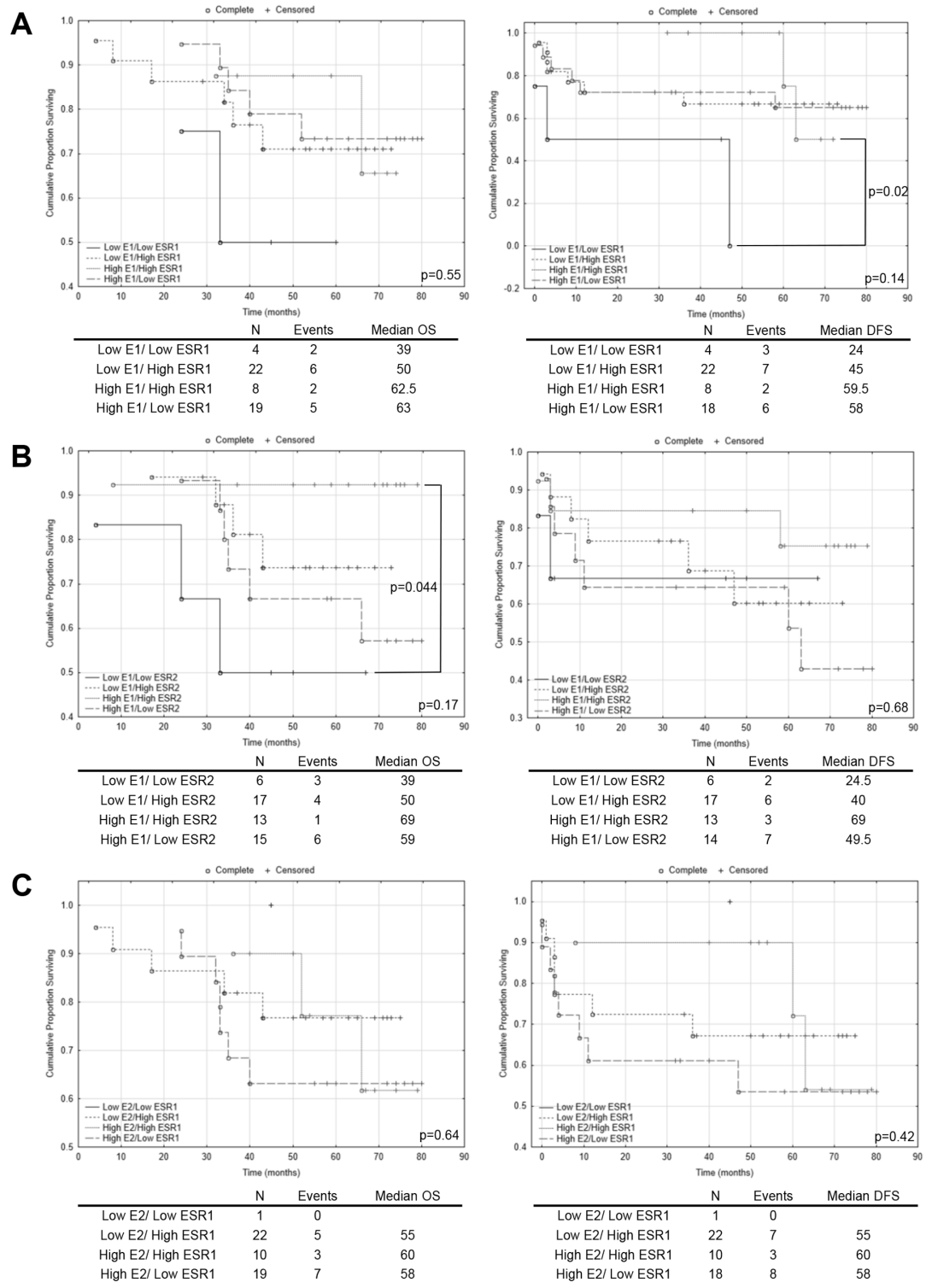

D
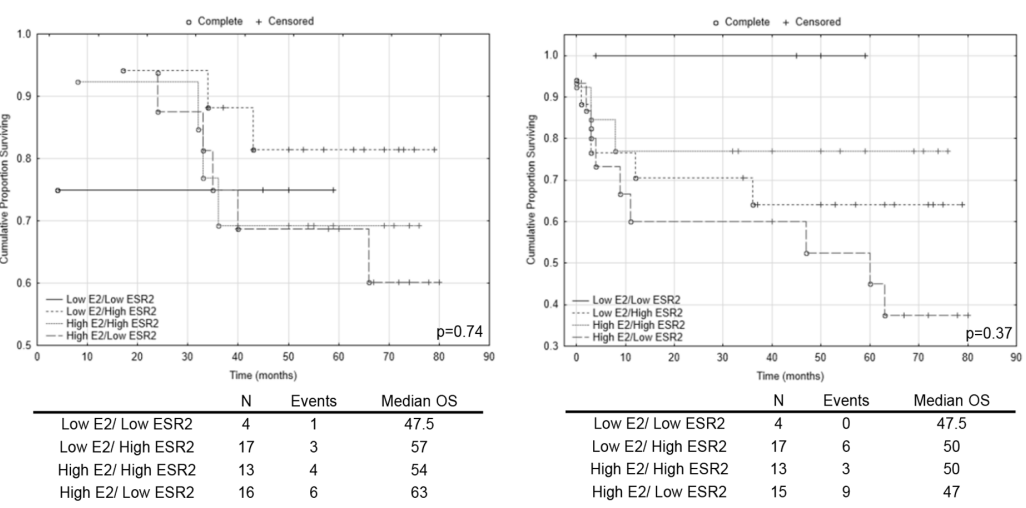

Figure 4: The Kaplan-Meier survival analysis among patients with colorectal cancer according to the estrogen concentration coupled with estrogen receptor transcript level. Patients samples from colorectal cancerous tissue were subdivided into four categorical groups: low E1(E2) and low ESR1(ESR2); low E1(E2) and high ESR1(ESR2); high E1(E2) and high ESR1(ESR2); high E1(E2) and low ESR1(ESR2). (A) - comparison of categorical groups for E1/ESR1; (B) - comparison of categorical groups for E1/ ESR2; (C) - comparison of categorical groups for E2/ESR1; (D) - comparison of categorical groups for E2/ESR2. p values for overall (OS) and disease free survival (DFS) for multiple groups comparison were given in each graph bottom right. Individual comparison of 2 groups was determined with the log rank test and given only for significant results. N, number of patients. 
Table 1: Multivariate analysis of E1/ESR1 and E1/ESR2 groups in cancerous tissue in patients with colorectal cancer

\begin{tabular}{lllllll}
\hline \multirow{2}{*}{ Variable } & \multicolumn{2}{c}{ OS } & & & DFS \\
\cline { 2 - 3 } \cline { 5 - 6 } & HR $(95 \%$ CI $)$ & p & HR (95\% CI) & p \\
\hline
\end{tabular}

E1/ESR1

Low E1/Low ESR1

1

Low E1/High ESR1

$0.29(0.05-1.73)$

0.17

High E1/High ESR1

0.32 (0.04-2.53)

0.28

$0.15(0.02-1.25)$

0.08

$0.23(0.05-0.97)$

0.04

High E1/Low ESR1

Gender

Male

1

Female

$0.93(0.22-3.99)$

0.92

$0.16(0.02-1.05)$

0.06

Age

below 60

1

above 60

$1.08(0.02-5.78)$

0.93

0.25 (0.06-1.16)

0.08

Therapy

no

1

yes

$1.31(0.35-4.97)$

0.69

$1.14(0.40-3.31)$

0.79

Variable

HR (95\% CI)

OS

E1/ESR2

Low E1/Low ESR2

1

Low E1/High ESR2

$0.41(0.07-2.54)$

0.34

High E1/High ESR2

0.13 (0.01-1.91)

0.14

High E1/Low ESR2

$0.56(0.09-3.47)$

0.54

\section{Gender}

Male

Female

1

Age

below 60

$1.22(0.27-5.47)$

0.80

above 60

$0.84(0.16-4.35)$

0.84

Therapy

no

yes

$1.13(0.30-4.35)$

0.85

OS- overall survival; DFS- disease free survival; HR- hazard ratio; CI- confidence intervals.

of local E1 and E2 concentrations. In this study we have not indicated statistically significant differences in analyzed estrogens concentrations between cancerous and adjacent histopathologically unchanged tissue. Even though E1 and E2 levels were correlated, ratio of E1 to E2 was significantly higher in cancerous tissue compared with histopathologically unchanged. The achieved data resemble only one similar report where $53 \mathrm{CRC}$ patients' samples were analyzed [27]. Sato et al. observed statistically significant 2-fold higher E1 concentration in cancerous tissue [27]. Our data follow this trend with statistically insignificant 1.5- higher E1 concentration in cancerous tissue compared with histopathologically unchanged. However, we have observed statistically 


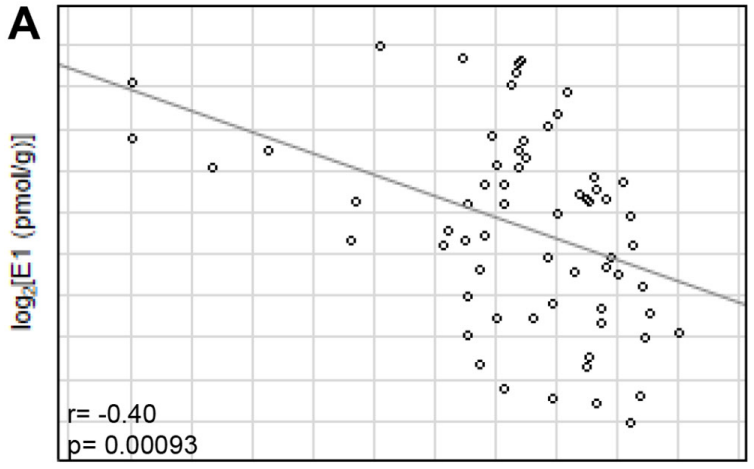

$\log _{2}[$ CTNNB1 mRNA]

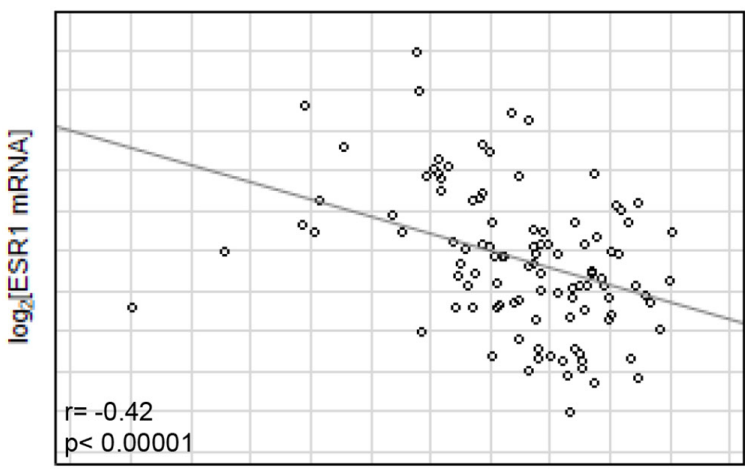

$\log _{2}[\mathrm{CTNNB} 1 \mathrm{mRNA}]$

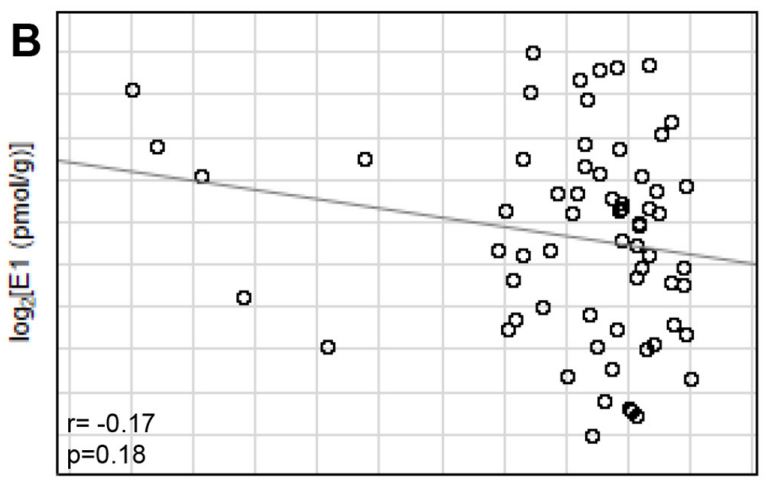

$\log _{2}[\mathrm{CCND} 1 \mathrm{mRNA}]$

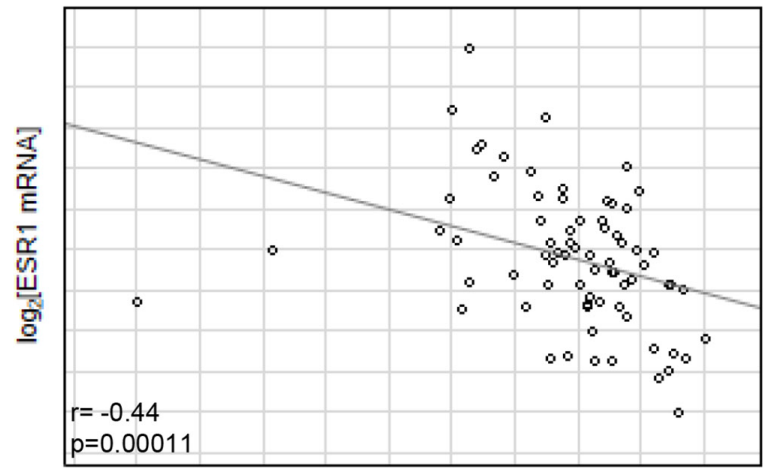

$\log _{2}[\mathrm{CCND} 1 \mathrm{mRNA}]$

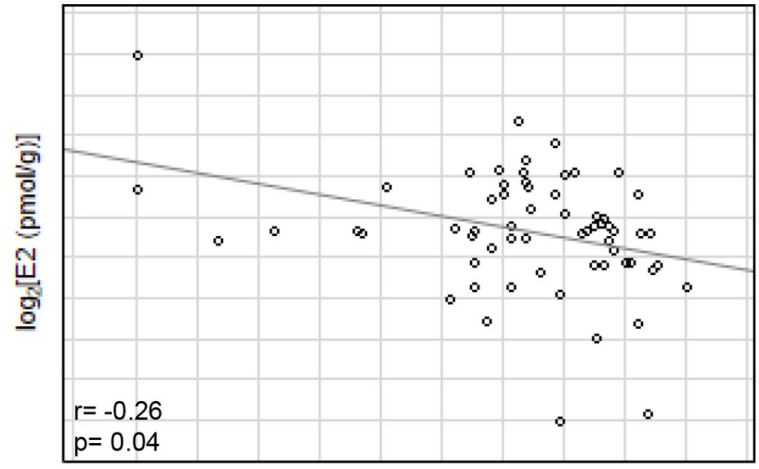

$\log _{2}[$ CTNNB1 mRNA]

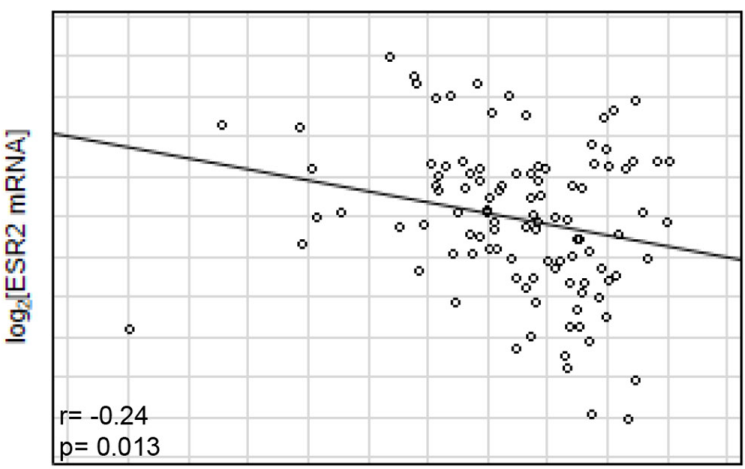

$\log _{2}[\mathrm{CTNNB} 1 \mathrm{mRNA}]$

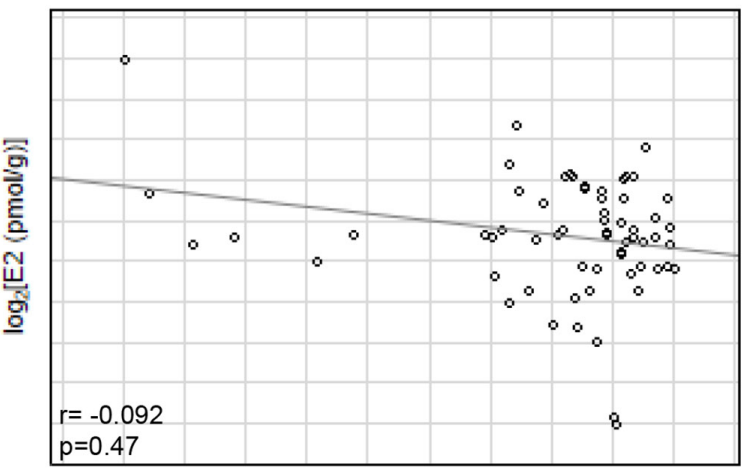

$\log _{2}[\mathrm{CCND} 1 \mathrm{mRNA}]$

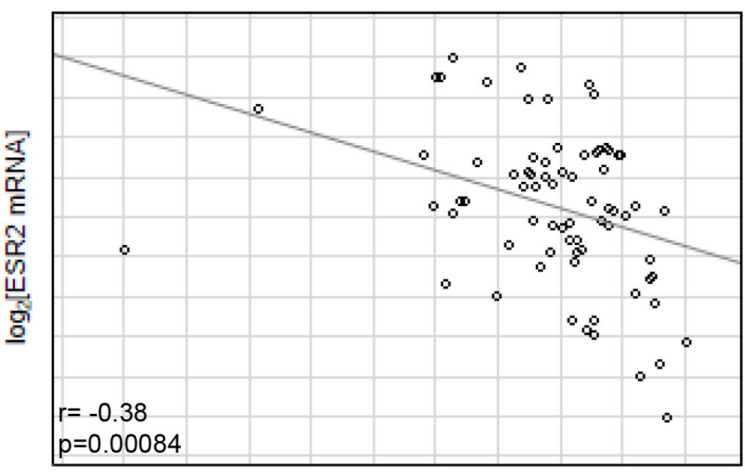

$\log _{2}[\mathrm{CCND} 1 \mathrm{mRNA}]$

Figure 5: Correlation of estrogen concentration (E1/E2) or estrogen receptor transcript level (ESR1/ESR2) with CTNNB1 (A) and CCND1 transcript level (B) from cancerous tissues of CRC patients. 
significant higher E1 concentration within cancerous tissue for patients above 60 yrs old, regardless of their gender. In context of intratissue estrogen metabolism, higher E1 concentration and alterations in E1 to E2 ratio in cancerous tissue may follow our previous observations. Expression of $17 \beta$ - hydroxydehydrogenase type 1
(HSD17 $\beta 1)$ - gene encoding main enzyme responsible for converting E1 into E2 was reduced in CRC tissue [24]. However, English et al. found in CRC loss of HSD17 32 expression responsible for oxidation E2 to E1 [26]. Our data suggest also decrease of E1-S desulfonation enzyme [28]. The conflicting data from previous reports as
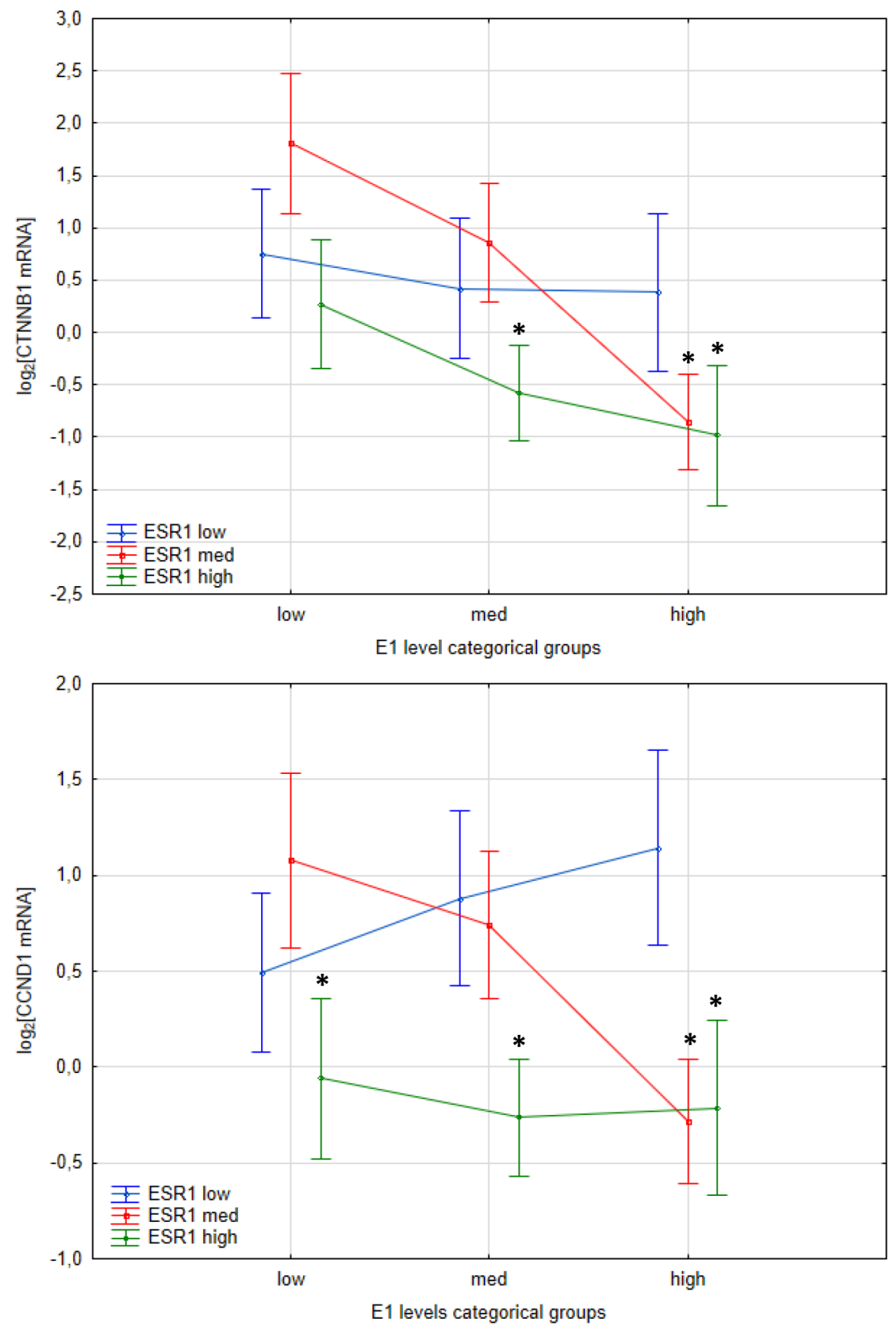

Figure 6: Interaction plots from two-way ANOVA presenting effect of E1 concentration level and ESR1 status on CTNNB1 and CCND1 mRNA expression level in cancerous tissues of CRC patients. Values are means \pm SE. Post-hoc p-values: CTNNB1: low E1-low ESR1 vs. high E1-high ESR1 p=0.06; low E1-med ESR1 vs. high E1-high ESR1 p=0.005; low E1-med ESR1 vs med E1-high ESR1 p=0.005; low E1-med ESR1 vs high E1-med ESR1 p=0.001. CCND1: high E1-low ESR1 vs low E1-high ESR1 p=0.073; high E1-low ESR1 vs med E1-high ESR1 p=0.022; high E1-low ESR1 vs high E1-high ESR1 p=0.05; low E1-med ESR1 vs high E1-med ESR1 p=0.022. 
well observed in this study high divergence of estrogen concentrations among tissues suggests that the intratissue E1 and E2 level may be affected by etiological factors like obesity. Adipose tissue contributes meaningfully to extragonadal steroid hormones production and may regulate amount of precursors available for estrogen metabolism in colon tissues [29]. Moreover, actual Km values of enzymes involved in estrogen metabolism, not only their amount, should be investigated in future more deeply in CRC tissue. Furthermore, in contradiction to the Sato report we have not observed any effect of the E1 or E2 concentration on CRC patients' clinical outcome [27]. The discrepancies might be an effect of the different group size or patient's medical history. Our study enrolled only women that were non- contraceptive users and have not taken HRT, which was not pointed out in the referred publication.

Estrogen action is mediated by its specific receptors which implication in CRC has been also widely investigated. ER type $\alpha$ and $\beta$ are nuclear receptors that after dimerization and ligand binding translocate to nucleus where initiate transcription of genes containing estrogen response element (ERE) in the promoter region [30]. Moreover, ERs can cross-talk with other transcription factors complexes and affect non-ERE containing genes. In colon mainly expressed form is ER- $\beta$ with limited expression of ER- $\alpha$ [12]. Overwhelming amount of evidence, summarized in recent review, prove inverse relationship of ER- $\beta$ presence with occurrence of $\mathrm{CRC}$ or familial adenomatous polyposis [13]. Immunohistochemistry based studies of large group of CRC patients' associate low ER- $\beta$ expression with poorer OS and DFS survival [31-33]. Additionally, studies on IBD presented lower ESR2 expression levels in colonic mucosa of Crohn's disease (CD) and ulcerative colitis (UC) patients compare with controls [34, 35]. Reduced ESR1 expression caused by DNA hypermethylation in promoter region was also observed in UC patients with neoplastic regions [36]. In line with previous reports, transcript levels of ESR1 and ESR2 were reduced in our study in cancerous tissue compared with histopathologically unchanged. However, ESR1 and ESR2 transcript levels presented lack of impact on patient survival. To best of our knowledge, this is first report investigating ESR1 next to ESR2 mRNA level in context of CRC patients' survival.

Even though ESR2 seems to be main isoform expressed in colon we have observed that mRNA levels of both: ESR1 and ESR2 were reduced and correlated which suggest that decrease of both may occur equivalently during CRC progression. To date, in vitro studies focused on ESR2 expression effect on CRC cells proliferation and expression of oncogenes or tumor suppressors, revealing it protective role [13]. For example, ER- $\beta$ has been shown to induce apoptosis in CRC cell lines through upregulation of p53 signalling and regulation G1- specific cell cycle genes [37, 38]. In vitro data regarding ESR1 expression are limited. One report suggests that overexpression of ESR1 in CRC cell lines have antiproliferative function [39]. More data regarding function of both receptors in $\mathrm{CRC}$ is available from in vivo studies. $\mathrm{Apc}^{\mathrm{Min} /+}$ mice knockouts for ER- $\alpha$ or $-\beta$ had higher tumour formation than respective controls in independent experiments [10, 11, 40, 41]. Correspondingly, treatment $\mathrm{Apc}^{\mathrm{Min} /+}$ mice with ER- selective agonists resulted in repression of CRC development $[42,43]$.

To identify actual estrogen responsive CRC tissue and predict impact on patient clinical outcome we performed categorical clustering of E1 and E2 concentration with ERs transcript levels. Interestingly, log rank test revealed beneficial DFS effect of coupled high E1 intratissue concentration with high ESR1 mRNA level compared with respective low E1 and ESR1 group. Additionally, multivariable analysis suggests that E1 concentration coupled with ESR1 transcript status might be independent prognostic factor. Even though results have to be validated in large studies with extended follow up, the findings are biologically plausible and for the first time link local estrogen concentration with ER status. Although E1 is not main biologically active form of estrogen, it may bind to ERs [44]. Moreover, E1 was shown to have antiproliferative effects in CRC cells [26] and decrease carcinogen induced- CRC incidence in ovariectomized mice [7]. Surprisingly no statistically significant correlation was found for category of E2 together with any of ER isoform. Observed result could be an effect of limited number of patients in given groups. Subgroup: low E2/low ESR1 had only one patient case and group: low E2/low ESR2 contained mostly censored data. Based on that we could not have evaluated this intriguing issue. To date, only one study presented significant lower CRC risk for patient with HRT history use coupled with ESR2-positive immunohistochemistry staining [45].

To verify protective effect of E1 coupled with ESR1 we have evaluated estrogen dependent mechanisms involved in CRC. Aberrant activation of Wnt signalling pathway is frequently observed in CRC [46] and former studies suggested influence of estrogenic pathway on Wnt in CRC. $\beta$-catenin expression in $\mathrm{Apc}^{\mathrm{Min} /+}$ mice was higher in ER- $\alpha$ deficient mice, but not ER- $\beta$, that followed upregulation of Wnt activated genes including cyclin D1 and c-myc $[11,47]$. Supporting observations from in vivo studies we have detected the highest transcript level of cyclin D1 and $\beta$-catenin in CRC patients with low or intermediate ESR1 transcript level together with low E1 concentration. The similar trend was also observed for $\beta$-catenin transcript level with E1-ESR2 subgroups but not for E2-ESR2 classification for both genes. Expression of $\beta$-catenin and cyclin D1 might be upregulated in CRC in independently of estrogenic pathway, nevertheless the 
inverse relation of their expression to E1-ESR1 status follow previous observation on animal models. Hence, it seems that in opposition to Wnt-estrogen regulation in breast cancer [48], ER- $\alpha$ has different effects in colon. Still, exact molecular mechanisms of ligand dependent ER- $\alpha$ action in CRC are not deeply described.

Present study for the first time provides evidence for association between intratissue estrogen concentrations coupled with estrogen receptor status. Importantly, it indicates potential prognostic values for etiological factor combined with molecular changes. Unfortunately, due to small amount of tissue sample we could have not assess ER protein levels. Limitation of our analysis could be also lack of more detailed data on other factors, both etiological and molecular, that may influence local estrogen synthesis. Future studies in large CRC patient cohort should stratify for other factors as well measure intratissue activity of enzymes involved in steroidogenesis in CRC tissue.

In conclusion, our data associate high ESR1 mRNA level together with high E1 intratissue concentration with better DFS of CRC patients. The protective effects of E1ESR1 might be switched off in subgroup of CRC patients, indicated by higher expression of $\beta$-catenin and cyclin D1, possibly explaining correlation of high ESR1-E1 level with better DFS. These results are in line with hypotheses presented mostly in animal studies and emphasize significance of tissue estrogen concentration in relation to ERs expression. Moreover, data suggest potential usage of these factors for clinics, either as biomarkers or as targets for estrogen related therapeutics.

\section{MATERIALS AND METHODS}

\section{Patient material}

Primary colonic adenocarcinoma tissues were collected between June 2009 and March 2013 from one hundred ten patients who underwent radical surgical resection of the colon at the Department of General and Colorectal Surgery, Poznań University of Medical Sciences, Poland (Supplementary Table 5). The histopathologically unchanged colonic mucosa located at least $10-20 \mathrm{~cm}$ away from the cancerous lesions was obtained from the same patients. One set of samples was immediately snap-frozen in liquid nitrogen and stored at $-80^{\circ} \mathrm{C}$ until estrogen/RNA isolation. The other set of samples was directed for histopathological examination. Histopathological classification was performed by an experienced pathologist. None of analyzed patients received preoperative chemo- or radiotherapy. All females were in postmenopausal age and none was using oral contraceptives or received hormone replacement therapy. An informed consent was obtained from all participating individuals. The procedures of the study were approved by the Local Ethical Committee of Poznań University of Medical Sciences.

\section{Measurement of overall and disease free survival}

Follow-up data were available for eighty two patients, who were observed from 2009/08/11 until death or 2016/02/10, whichever came first. Disease free survival (DFS) is defined as the time elapsed from surgery to the first occurrence of any of the following events: recurrence or distant metastasis of CRC or development of a second non-colorectal malignancy.

\section{Liquid chromatography electrospray ionization tandem mass spectrometry analysis (ESI LC/MS)}

Tissue specimens (up to $40 \mathrm{mg}$ per sample) were homogenized in Freezer/Mill, SPEX SamplePrep (Metuchen NY, USA) and dissolved in $1 \mathrm{ml}$ of distilled water. At this step C13 derivatives of E1 and E2 were added to each sample as internal standards. Steroid fraction was extracted from tissue using diethyl ether. Obtained organic layer was evaporated and subsequently derivatized with dansyl chloride [49, 50].

All samples were analyzed using an LC/MS system built on Waters Nano Acquity UPLC, Waters (Milford MA, US) combined with a Ion Trap mass spectrometer, model Amazon SL, Bruker Daltonics (Bremen, Germany). Analyses were carried out using nanoAcquity Symmetry C18 column, Waters $(3.5 \mu \mathrm{m}$, $150 \mu \mathrm{m} \times 150 \mathrm{~mm})$. Chromatographic separation was performed at a flow rate of $8 \mu \mathrm{L} / \mathrm{min}$ using mixtures of the following two solvents: A $(99.5 \% \mathrm{H} 2 \mathrm{O}, 0.5 \%$ formic acid (v/v)) and B (99.5\% acetonitrile, $0.5 \%$ formic acid $(\mathrm{v} / \mathrm{v}))$. The column effluent was introduced into an ESI ion source using the gradient as follows: 0-5 min isocratic separation at $5 \% \mathrm{~B}, 5-15 \mathrm{~min}$ gradient from 5 to $45 \% \mathrm{~B}, 15-20 \mathrm{~min}$ linear gradient to $95 \% \mathrm{~B}, 20-25 \mathrm{~min}$ of isocratic flow at $95 \% \mathrm{~B}$ and for 5 additional min return to the initial conditions.

The Amazon SL spectrometer consisted of ESI operating at $-4.5 \mathrm{kV}$, nebulization with nitrogen at 1.6 bar and a dry gas flow of $8.0 \mathrm{~L} / \mathrm{min}$ at a temperature of $220^{\circ} \mathrm{C}$. The analyser operated at MRM mode, 4 different transitions were measured simultaneously: 504->171 and 506->171 for E1; 507->171 and 509->171 for E2 (Supplementary Figure 4). The instrument was scanning in Enhanced Resolution mode under the control of trapControl version 7.1, and data were analyzed using the DataAnalysis version 4.1 package supplied by Bruker Daltonics. Profiles of E1, E2 and their deuterated forms were extracted for specific transitions and areas under peaks were measured. Quantitative analysis was performed by preparation of calibration curve for E1 and E2 in concentration range from $10 \mathrm{fg} / \mathrm{ml}$ to $10 \mathrm{ng} /$ $\mathrm{ml}$. The curve showed high linearity in given range $\left(\mathrm{R}^{\wedge} 2\right.$ $>0.95)$ allowing confident measurement of E1 and E2 concentrations in the tissue samples. 


\section{Reverse transcription and real-time quantitative polymerase chain reaction (RQ-PCR) analysis}

Total RNA from tissues of patients with CRC was isolated according to the method of Chomczyński and Sacchi [51]. The $1 \mu \mathrm{g}$ of each RNA sample was reversetranscribed into cDNA using SuperScript ${ }^{\mathrm{TM}}$ reverse trascriptase, ThermoFisher Scientific (Waltham, USA). RT-qPCR was carried out in the Light Cycler ${ }^{\circledR} 480$ RealTime PCR System, Roche Diagnostics GmbH (Mannheim, Germany) using EvaGreen as the detection dye. The target cDNA was quantified by the relative quantification method using a calibrator. The calibrator was prepared as a cDNA mix from all of the patients' samples, and successive dilutions were used to create a standard curve as described in Relative Quantification Manual Roche Diagnostics $\mathrm{GmbH}$, (Mannheim, Germany). For amplification, $1 \mu \mathrm{l}$ of (total $20 \mu \mathrm{l}$ ) cDNA solution was added to $9 \mu \mathrm{l}$ of $5 \mathrm{X}$ Hot FIREPol EvaGreen HRM Mix, Solis BioDyne Co. (Tartu, Estonia) with primers (Supplementary Table 6). To prevent amplification of sequences from genomic DNA contamination, primers and/or amplicons were designed at exon/exon boundaries and covered all gene splice variants. The quantity of ESR1, ESR2, CTNB1 and CCND1 transcripts in each sample was standardized by the geometric mean of two internal controls: porphobilinogen deaminase $(P B G D)$ and human mitochondrial ribosomal protein L19 (hMRPL19) (Supplementary Table 6). The selection of internal control genes was made as previously [23]. The ESR1, ESR2, CTNB1 and CCND1 transcript level in the patients' tissues were expressed as multiplicity of the cDNA concentrations in the calibrator.

\section{Statistical analysis}

The normality of the observed patient data distribution was assessed by Shapiro-Wilk test, and the U Mann-Whitney test was used to compare the median values. Non-parametric Kruskal-Wallis test with posthoc multiple comparison of mean ranks was employed to evaluate the association between different categorical groups within cancerous or histopathologically unchanged tissue for estrogen concentrations and ESR1/ESR2 mRNA levels. Correlation between the analyzed data was performed using Spearman rank correlation coefficient. Additionally, two-way ANOVA following post-hoc test was performed to assess the interaction of estrogen-estrogen receptors and CTNNB1 or CCND1 transcript level.

Survival curves were plotted using the KaplanMeier method and survival differences were achieved using the log-rank test. Multivariate Cox proportional hazard model was used to estimate the adjusted hazard ratio (HR).

Statistically significant results were indicated by $p<$ 0.05 . Statistical analysis was performed with STATISTICA 10.0 software.

\section{Abbreviations}

CCND1: cyclin D1; CTNBB1: $\beta$-catenin; CRC: colorectal cancer; DFS: disease free survival; E1: estrone; E1-S: estrone sulfate; E2: 17ß- estradiol; ER (gene ESR1, ESR2): estrogen receptor; ESI LC/MS: Liquid chromatography electrospray ionization tandem mass spectrometry; hMRPL19: human mitochondrial ribosomal protein L19; HR: hazard ratio; HRT: hormone replacement therapy; HSD17 $\beta \mathrm{s}: 17 \beta$-hydroxysteroid dehydrogenases; OS: overall survival; PBGD: porphobilinogen deaminase; RQ-PCR: real-time quantitative polymerase chain reaction.

\section{Author contributions}

ARW conceived and designed the experiments, performed the experiments and analyzed the data and wrote the manuscript. LM performed ESI LC/MS experiments and analyzed the data. $\mathrm{NH}, \mathrm{KH}$ and $\mathrm{PK}$ collected and analyzed clinic samples. PPJ participated in design and coordination of study. All authors read and approved the final manuscript.

\section{CONFLICTS OF INTEREST}

No potential conflicts of interest were disclosed.

\section{FUNDING}

This work is supported by National Science Centre, Poland; 2012/05/N/NZ5/00844.

\section{REFERENCES}

1. Siegel R, Miller K, Jemal A. Cancer statistics, 2015. CA Cancer J Clin. 2015; 65: 29. https://doi.org/10.3322/ caac. 21254.

2. Ries LA, Wingo PA, Miller DS, Howe HL, Weir HK, Rosenberg HM, Vernon SW, Cronin K, Edwards BK. The annual report to the nation on the status of cancer, 19731997, with a special section on colorectal cancer. Cancer. 2000; 88: 2398-424. https://doi.org/10.1002/(SICI)10970142(20000515)88:10<2398::AID-CNCR26>3.0.CO;2-I.

3. Brenner H, Hoffmeister M, Arndt V, Haug U. Gender differences in colorectal cancer: implications for age at initiation of screening. Br J Cancer. 2007; 96: 828-31. https://doi.org/10.1038/sj.bjc.6603628.

4. Qiu Y, Langman MJ, Eggo MC. Targets of 17betaoestradiol-induced apoptosis in colon cancer cells: a mechanism for the protective effects of hormone replacement therapy? J Endocrinol. 2004; 181: 32737. Available from http://www.ncbi.nlm.nih.gov/ pubmed/15128281. 
5. Nelson HD, Humphrey LL, Nygren P, Teutsch SM, Allan JD. Postmenopausal hormone replacement therapy: scientific review. JAMA. 2002; 288: 872-81. https://doi. org/10.1001/jama.288.7.872.

6. Rennert G, Rennert HS, Pinchev M, Lavie O, Gruber $\mathrm{SB}$. Use of hormone replacement therapy and the risk of colorectal cancer. J Clin Oncol. 2009; 27: 4542-7. https:// doi.org/10.1200/JCO.2009.22.0764.

7. Guo JY, Li X, Browning JD, Rottinghaus GE, Lubahn DB, Constantinou A, Bennink M, MacDonald RS. Dietary soy isoflavones and estrone protect ovariectomized ERalphaKO and wild-type mice from carcinogen-induced colon cancer. J Nutr. 2004; 134: 179-82. Available from http://jn.nutrition. org/content/134/1/179.abstract.

8. Smirnoff P, Liel Y, Gnainsky J, Shany S, Schwartz B. The protective effect of estrogen against chemically induced murine colon carcinogenesis is associated with decreased $\mathrm{CpG}$ island methylation and increased mrna and protein expression of the colonic vitamin D receptor. Oncol Res Featur Preclin Clin Cancer Ther. 1999; 11: 255-64.

9. Foster PA. Oestrogen and colorectal cancer: mechanisms and controversies. Int J Colorectal Dis. 2013; 28: 737-49. https://doi.org/10.1007/s00384-012-1628-y.

10. Giroux V, Lemay F, Bernatchez G, Robitaille Y, Carrier JC. Estrogen receptor $\beta$ deficiency enhances small intestinal tumorigenesis in ApcMin/+ mice. Int J Cancer. 2008; 123: 303-11. https://doi.org/10.1002/ijc.23532.

11. Cleveland AG, Oikarinen SI, Bynoté KK, Marttinen M, Rafter JJ, Gustafsson JÅ, Roy SK, Pitot HC, Korach KS, Lubahn DB, Mutanen M, Gould KA. Disruption of estrogen receptor signaling enhances intestinal neoplasia in ApcMin/+ mice. Carcinogenesis. 2009; 30: 1581-90. https://doi.org/10.1093/carcin/bgp132.

12. Elbanna HG, Ebrahim MA, Abbas AM, Zalata K, Hashim MA. Potential value of estrogen receptor beta expression in colorectal carcinoma: interaction with apoptotic index. J Gastrointest Cancer. 2012; 43: 56-62. https://doi. org/10.1007/s12029-010-9214-4.

13. Williams C, DiLeo A, Niv Y, Gustafsson JÅ. Estrogen receptor beta as target for colorectal cancer prevention. Cancer Lett. 2016; 372: 48-56. https://doi.org/10.1016/j. canlet.2015.12.009.

14. Lin KJ, Cheung WY, Lai JY, Giovannucci EL. The effect of estrogen vs. combined estrogen-progestogen therapy on the risk of colorectal cancer. Int J Cancer. 2012; 130: 419-30. https://doi.org/10.1002/ijc.26026.

15. Barzi A, Lenz AM, Labonte MJ, Lenz HJ. Molecular pathways: estrogen pathway in colorectal cancer. Clin Cancer Res. 2013; 19: 5842-8. https://doi. org/10.1158/1078-0432.CCR-13-0325.

16. Gunter MJ, Hoover DR, Yu H, Wassertheil-Smoller S, Rohan TE, Manson JE, Howard BV, Wylie-Rosett J, Anderson GL, Ho GY, Kaplan RC, Li J, Xue X, et al. Insulin, insulin-like growth factor-I, endogenous estradiol, and risk of colorectal cancer in postmenopausal women. Cancer Res. 2008; 68: 329-37. https://doi. org/10.1158/0008-5472.CAN-07-2946.

17. Clendenen TV, Koenig KL, Shore RE, Levitz M, Arslan AA, Zeleniuch-Jacquotte A. Postmenopausal levels of endogenous sex hormones and risk of colorectal cancer. Cancer Epidemiol Biomarkers Prev. 2009; 18: 275-81. https://doi.org/10.1158/1055-9965.EPI-08-0777.

18. Falk RT, Dallal CM, Lacey JV, Bauer DC, Buist DS, Cauley JA, Hue TF, LaCroix AZ, Tice JA, Pfeiffer RM, Xu X, Veenstra TD, Brinton LA. Estrogen metabolites are not associated with colorectal cancer risk in postmenopausal women. Cancer Epidemiol Biomarkers Prev. 2015; 24: $1419-22$.

19. Lin JH, Zhang SM, Rexrode KM, Manson JE, Chan AT, $\mathrm{Wu}$ K, Tworoger SS, Hankinson SE, Fuchs C, Gaziano JM, Buring JE, Giovannucci E. Association between sex hormones and colorectal cancer risk in men and women. Clin Gastroenterol Hepatol. 2013; 11: 419-424.e1. https:// doi.org/10.1016/j.cgh.2012.11.012.

20. Murphy N, Strickler HD, Stanczyk FZ, Xue X, Wassertheil-Smoller S, Rohan TE, Ho GY, Anderson GL, Potter JD, Gunter MJ. A prospective evaluation of endogenous sex hormone levels and colorectal cancer risk in postmenopausal women. J Natl Cancer Inst. 2015; 107: djv210. https://doi.org/10.1093/jnci/djv210.

21. Bábíčková J, Tóthová L, Lengyelová E, Bartoňová A, Hodosy J, Gardlík R, Celec P. Sex differences in experimentally induced colitis in mice: a role for estrogens. Inflammation. 2015; 38: 1996-2006. https://doi. org/10.1007/s10753-015-0180-7.

22. Kane SV, Reddy D. Hormonal replacement therapy after menopause is protective of disease activity in women with inflammatory bowel disease. Am J Gastroenterol. 2008; 103: 1193-6. https://doi.org/10.1111/j.1572-0241.2007.01700.x.

23. Rawluszko AA, Bujnicka KE, Horbacka K, Krokowicz P, Jagodziński PP, Jagodzinski PP. Expression and DNA methylation levels of prolyl hydroxylases PHD1, PHD2, PHD3 and asparaginyl hydroxylase FIH in colorectal cancer. BMC Cancer. 2013; 13: 526. https://doi. org/10.1186/1471-2407-13-526.

24. Rawłuszko AA, Horbacka K, Krokowicz P, Jagodziński PP. Decreased expression of 17 $\beta$-hydroxysteroid dehydrogenase type 1 is associated with DNA hypermethylation in colorectal cancer located in the proximal colon. BMC Cancer. 2011; 11: 522. https://doi. org/10.1186/1471-2407-11-522.

25. English MA, Hughes SV, Kane KF, Langman MJ, Stewart PM, Hewison M. Oestrogen inactivation in the colon: analysis of the expression and regulation of $17 \mathrm{beta}-$ hydroxysteroid dehydrogenase isozymes in normal colon and colonic cancer. Br J Cancer. 2000; 83: 550-8. https:// doi.org/10.1054/bjoc.2000.1324.

26. English MA, Kane KF, Cruickshank N, Langman MJ, Stewart PM, Hewison M. Loss of estrogen inactivation in 
colonic cancer. J Clin Endocrinol Metab. 1999; 84: 2080-5. https://doi.org/10.1210/jcem.84.6.5772.

27. Sato R, Suzuki T, Katayose Y, Miura K, Shiiba K, Tateno H, Miki Y, Akahira J, Kamogawa Y, Nagasaki S, Yamamoto K, Ii T, Egawa S, et al. Steroid sulfatase and estrogen sulfotransferase in colon carcinoma: regulators of intratumoral estrogen concentrations and potent prognostic factors. Cancer Res. 2009; 69: 914-22. https://doi. org/10.1158/0008-5472.CAN-08-0906.

28. Rawłuszko AA, Antoniucci M, Horbacka K, Lianeri M, Krokowicz P, Jagodziński PP. Reduced expression of steroid sulfatase in primary colorectal cancer. Biomed Pharmacother. 2013; 67: 577-82. https://doi.org/10.1016/j. biopha.2013.04.007.

29. Sikalidis AK, Varamini B. Roles of hormones and signaling molecules in describing the relationship between obesity and colon cancer. Pathol Oncol Res. 2011; 17: 785-90. https://doi.org/10.1007/s12253-010-9352-9.

30. Ascenzi P, Bocedi A, Marino M. Structure-function relationship of estrogen receptor alpha and beta: impact on human health. Mol Aspects Med. 2006; 27: 299-402. https://doi.org/10.1016/j.mam.2006.07.001.

31. Rudolph A, Toth C, Hoffmeister M, Roth W, Herpel E, Jansen L, Marx A, Brenner H, Chang-Claude J. Expression of oestrogen receptor beta and prognosis of colorectal cancer. Br J Cancer. 2012; 107: 831-9. https://doi. org/10.1038/bjc.2012.323.

32. Fang YJ, Lu ZH, Wang F, Wu XJ, Li LR, Zhang LY, Pan ZZ, Wan DS. Prognostic impact of ERbeta and MMP7 expression on overall survival in colon cancer. Tumour Biol. 2010; 31: 651-8. https://doi.org/10.1007/ s13277-010-0082-0.

33. Fang Y, Zhang L, Wu X, Lu Z, Li J, Ou Q, Zhang M, Ding P, Pan Z, Wan D. Impact of ER $\beta$ and CD44 expression on the prognosis of patients with stage II colon cancer. Tumour Biol. 2012; 33: 1907-14.

34. Looijer-van Langen M, Hotte N, Dieleman LA, Albert E, Mulder C, Madsen KL. Estrogen receptor- $\beta$ signaling modulates epithelial barrier function. Am J Physiol Gastrointest Liver Physiol. 2011; 300: G621-6. https://doi. org/10.1152/ajpgi.00274.2010.

35. Pierdominici M, Maselli A, Varano B, Barbati C, Cesaro P, Spada C, Zullo A, Lorenzetti R, Rosati M, Rainaldi G, Limiti MR, Guidi L, Conti L, et al. Linking estrogen receptor $\beta$ expression with inflammatory bowel disease activity. Oncotarget. 2015; 6: 40443-51. https://doi. org/10.18632/oncotarget.6217.

36. Tominaga K, Fujii S, Mukawa K, Fujita M, Ichikawa K, Tomita S, Imai Y, Kanke K, Ono Y, Terano A, Hiraishi H, Fujimori T. Prediction of colorectal neoplasia by quantitative methylation analysis of estrogen receptor gene in nonneoplastic epithelium from patients with ulcerative colitis. Clin Cancer Res. 2005; 11: 8880-5. https://doi. org/10.1158/1078-0432.CCR-05-1309.
37. Hsu H, Cheng S, Wu C, Chu C, Weng Y, Lin C, Lee S, Wu $\mathrm{H}$, Huang C, Kuo W. Apoptotic effects of over-expressed estrogen receptor-beta on LoVo colon cancer cell is mediated by p53 signalings in a ligand-dependent manner. Chin J Physiol. 2006; 49: 110-6.

38. Hartman J, Edvardsson K, Lindberg K, Zhao C, Williams C, Ström A, Gustafsson JÅ. Tumor repressive functions of estrogen receptor beta in SW480 colon cancer cells. Cancer Res. 2009; 69: 6100-6. https://doi.org/10.1158/0008-5472. CAN-09-0506.

39. Issa JP, Ottaviano YL, Celano P, Hamilton SR, Davidson NE, Baylin SB. Methylation of the oestrogen receptor $\mathrm{CpG}$ island links ageing and neoplasia in human colon. Nat Genet. 1994; 7: 536-40. https://doi.org/10.1038/ ng0894-536.

40. Weyant MJ, Carothers AM, Mahmoud NN, Bradlow HL, Remotti H, Bilinski RT, Bertagnolli MM. Reciprocal expression of ERalpha and ERbeta is associated with estrogen-mediated modulation of intestinal tumorigenesis. Cancer Res. 2001; 61: 2547-51.

41. Cho NL, Javid SH, Carothers AM, Redston M, Bertagnolli MM. Estrogen receptors alpha and beta are inhibitory modifiers of Apc-dependent tumorigenesis in the proximal colon of Min/+ mice. Cancer Res. 2007; 67: 2366-72. https://doi.org/10.1158/0008-5472.CAN-06-3026.

42. Giroux V, Bernatchez G, Carrier JC. Chemopreventive effect of ER $\beta$-Selective agonist on intestinal tumorigenesis in Apc(Min/+) mice. Mol Carcinog. 2011; 50: 359-69. https://doi.org/10.1002/mc.20719.

43. Janakiram NB, Mohammed A, Zhang Y, Brewer M, Bryant T, Lightfoot S, Steele VE, Rao CV. Chemopreventive efficacy of raloxifene, bexarotene, and their combination on the progression of chemically induced colon adenomas to adenocarcinomas in rats. Cancer Prev Res. 2013; 6: 125161. https://doi.org/10.1158/1940-6207.CAPR-13-0249.

44. Ruh TS, Katzenellenbogen B, Katzenellenbogen J, Gorski J. Estrone interaction with the rat uterus: in vitro response and nuclear uptake. Endocrinology. 1973; 92: 125-34.

45. Rudolph A, Toth C, Hoffmeister M, Roth W, Herpel E, Schirmacher P, Brenner H, Chang-Claude J. Colorectal cancer risk associated with hormone use varies by expression of estrogen receptor- $\beta$. Cancer Res. 2013; 73: 3306-15. https://doi.org/10.1158/0008-5472.CAN-12-4051.

46. Cancer Genom Atlas Network. Comprehensive molecular characterization of human colon and rectal cancer. Nature. 2012; 487: 330-7. https://doi.org/10.1038/nature11252.

47. Hasson RM, Briggs A, Carothers AM, Davids JS, Wang J, Javid SH, Cho NL, Bertagnolli MM. Estrogen receptor?? or?? loss in the colon of Min/+ mice promotes crypt expansion and impairs TGF?? and HNF3?? signaling. Carcinogenesis. 2014; 35: 96-102. https://doi.org/10.1093/ carcin/bgt323. 
48. Katoh M. Expression and regulation of WNT1 in human cancer: up-regulation of WNT1 by beta-estradiol in MCF-7 cells. Int J Oncol. 2003; 22: 209-12.

49. Anari MR, Bakhtiar R, Zhu B, Huskey S, Franklin RB, Evans DC. Derivatization of ethinylestradiol with dansyl chloride to enhance electrospray ionization: application in trace analysis of ethinylestradiol in rhesus monkey plasma. Anal Chem. 2002; 74: 4136-44. https://doi.org/10.1021/ ac025712h.
50. Nelson RE. Liquid Chromatography-Tandem Mass Spectrometry Assay for Simultaneous Measurement of Estradiol and Estrone in Human Plasma. Clin Chem. 2004; 50: 373-84. https://doi.org/10.1373/clinchem.2003.025478.

51. Chomczynski P, Sacchi N. Single-step method of RNA isolation by acid guanidinium thiocyanate-phenolchloroform extraction. Anal Biochem. 1987; 162: 156-9. https://doi.org/10.1016/0003-2697(87)90021-2. 